\title{
TERRA SIGILLATA HISPÁNICA TARDÍA MERIDIONAL
}

\author{
POR \\ MARGARITA ORFILA \\ Departamento de Prehistoria y Arqueología. Universidad de Granada
}

\section{RESUMEN}

Se trata en este artículo de una posible producción de sigillatas hispánicas tardias en el sur de la península ibérica, que se propone denominar TSHTM. Se considera su vinculación con las sigillatas hispánicas y las norteafricanas y se estudia su dispersión geográfica. Parte de estas cerámicas se conocían hasta ahora como sigillatas paleocristianas de Cástulo y se relacionaban con las producciones tardias gálicas.

\section{SUMMARY}

This paper deals with the production of Late Hispanic Sigillata in the South of the Peninsula and proposes to denominate it as TSHTM. This kind of pottery has a clear relationship with the Hispanic and North-african Terra Sigillata and the author studies its geographic diffusion. Some part of this pottery was known until now as «sigillatas paleocristianas de Cástulo" and had been connected with the Late Gallic productions.

Dentro del mundo romano es de sobra conocida la diversidad de alfares de cerámicas finas o de vajilla que a lo largo del tiempo se han documentado. En este sentido es cada vez mas común la localización de producciones de sigillata clásica en Hispania y si nos centramos en la zona meridional el ejemplo queda perfectamente documentado '. Es lógico pensar en la continuidad de la tradición de esta actividad mas allá del siglo ॥ d. C. ${ }^{2}$

' Actualmente se conocen en la Bética diversidad de alfares de sigillata hispánica: Andújar (Roca, 1976; Sotomayor, 1977), Cartuja de Granada (Sotomayor, 1970; Serrano, 1979), Albaicín de Granada (Sotomayor; Sola; Choclán, 1984), Singilia Barba (Serrano, 1991); Antequera (Serrano, 1991), Alameda (Serrano; Atencia; Rodriguez, 1984) o las imitaciones de sigillatas clásicas que ya Domergue presentó (Domergue, 1967 y 1969), denominadas posteriormente por Martínez como cerámicas béticas de imitación tipo Peñaflor (Martinez, 1989).

${ }^{2}$ El final del siglo il d. C. es la fecha que generalmente se suele poner como tope a las producciones de sigillatas hispánicas altoimperiales, es decir, las clásicas (Mezquiriz, 1983, pág. 136). 
Referente a las producciones tardias de sigillatas hispánicas, sistematizadas por Palol en 1974 (Palol; Cortés, 1974), tenemos que decir que en los últimos años han tomado un gran auge las investigaciones sobre el tema, en especial debido a la cada vez mayor identificación de posibles producciones locales tardias ${ }^{3}$. Dentro de este apartado incluimos las que nosotros definimos como Terra Sigillata Hispánica Tardia Meridional (Orfila, en prensa) ${ }^{4}$, cuya identificación en parte ha sido conocida hasta ahora bajo la denominación de sigillatas paleocristianas de Cástulo (Molina, 1975; Blázquez, 1979; Molina, Huertas, Ocaña, 1980) y que en este artículo analizamos ${ }^{5}$.

Esta denominación se ha tomado de la propuesta hecha por Caballero en la que marcó una diferenciación entre dos posibles subproducciones tardias locales: «presencia de dos posibles subproducciones, una más meridional (Molina) tipificada por el burilado y otra más septentrional estampada (quizás intervienen en estas diferencias categorias cronológicas)» (Caballero, 1989, pág. 86).

Las sigillatas paleocristianas de Cástulo fueron relacionadas, como ya su denominación indica, con las sigillées paleochretiennes que Rigoir publicó en 1968, utilizando en parte esa tipologia gala para su catalogación ${ }^{6}$. Algo aventurada es, a nuestro entender, esta asociación como ya hemos indicado anteriormente (Orfila, en prensa) en parte por la poca difusión de esas producciones galas en esta zona de la Península y por otra debido a que algunas formas con las que se relacionan tienen una difusión escasa en el Mediterráneo ?

Consideramos que las piezas identificadas aquí como TSHTM tienen unas caracteristicas comunes que nos permiten hablar de unas cerámicas finas de vajilla en un marco geográfico de localización básicamente en el sur de la península ibérica, con identidad propia, estando justificada su inclusión dentro de la familia de sigillatas por las propias formas de las piezas, que da pie a formular una tipologia, y por su funcionalidad de vajilla ${ }^{8}$. En algunos casos se puede pensar en producciones de cerámicas comunes por la pérdida de parte de cali-

${ }^{3}$ Un buen ejemplo de ello lo tenemos en el número III del Boletín de Arqueología Medieval, monográfico sobre el tema, editado en 1989.

+ En la IV Reunión de Arqueología Cristiana celebrada en sep.-oct. de 1992 en Lisboa presentamos. a modo de introducción, estas producciones de sigillatas tardias meridionales, de hecho el propio titulo que propusimos refleja la provisionalidad de dicha comunicación: «¿Producciones de sigillatas no clásicas en la Bética? Las llamadas Sigillatas Paleocristianas de Cástulo», provisionalidad que también queda patente en este artículo tanto desde el punto de vista del número de formas identificadas, como de su cronología y dispersión geográfica.

5 Ya dedicamos en Lisboa (Orfila, en prensa) un apartado a la revisión del estudio de las cerámicas paleocristianas de Cástulo junto con sus tipologías, así como el realizado por Arteaga y Blech (1985) referentes a una serie de piezas que les parecian producciones locales imitando formas norteafricanas o hispánicas, halladas en la excavación de Cerro Maquiz, Jaén. Añadimos aqui la también asociación a estas producciones citadas por Arteaga y Blech de parte de los materiales de Begastri publicados por Ramallo (1984) como cerámicas tardías, grupos dos, tres, cuatro y cinco.

- Concretamente las formas Rigoir $1,3 b, 5 b, 8$ y 18.

7 Una mas completa información sobre este tema aparece en el apartado dedicado al estudio de cada una de las formas identificadas de TSHTM.

* Somos conscientes de que estas producciones se pueden alejar en algún aspecto de las sigillatas sensu stricto: no hay evidencias de la utilización del molde al fabricarse esta vajilla, ni la presencia de sellos que nos indiquen quién o quiénes fueron sus alfareros; o un proceso de fabricación oxidante tanto en el calentamiento y mantenimiento como en el proceso de enfriamiento. 
dad de su engobe o barniz en relación a otras producciones, en especial a la TSHT. Hay que añadir también la diferenciación que se aprecia en su morfometria, como queda detallado más adelante al hablar de las características especificas de estas producciones. Volviendo a la tipologia de las TSHTM, diremos que la mayoria de las formas que hasta la actualidad hemos identificado las relacionamos con formas de las sigillatas norteafricanas ", sin ser excluyente su asociación a otras producciones tardias, tanto hispánicas como de otros lugares; en este sentido ponemos como ejemplo la taza o bol identificado como forma número 2 de TSHTM y que relacionamos con la forma Drag. 37 de la TSHT, aunque la mayoria de estudios sobre producciones de sigillatas hispánicas tardias asocian sus tipologias a las de las gálicas "1".

Otra diferenciación estaría, como ya Caballero indicó, en su decoración. Las producciones meridionales presentan una decoración burilada, salvo excepciones, mientras que en las septentrionales domina la impresa realizada mediante punzones (Caballero, 1989, pág. 86). Buen ejemplo de estas últimas lo tenemos en las producciones localizadas en Salamanca (Cerrillo y Cerrillo, 1984/85), en Asturias (Carrocera y Requejo, 1989) o las procedentes de Cáceres, Madrid y Segovia (Caballero, 1989). Referente a la primera decoración, la burilada, no podemos olvidar lo frecuente que suele ser en las paredes finas, en la sigillata clásica, en las DSP gálicas, o en algunas piezas de producciones africanas, por poner algunos ejemplos.

Las características que macroscópicamente hemos podido apreciar en estas producciones de TSHTM, como ya indicamos en Lisboa (Orfila, en prensa), son las siguientes:

\footnotetext{
" Nos basamos en la documentación existente: están contabilizadas sigillatas africanas en yacimientos en donde hemos identificado TSHTM, diriamos que con un porcentaje mayor (de africanas) en las zonas costeras o de fácil acceso fluvial, y menor en zonas más interiores en donde aumenta la presencia de las sigillatas hispánicas tardias meridionales. Al mismo tiempo se comprueba la pobreza cuantitativa en la presencia de Sigillatas Paleocristianas (Derivées de les Sigillées Paleochretiennes) en esos mismos yacimientos. Recordemos también en este sentido la producción de piezas con formas de tipologías norteafricanas en otros lugares desde algunos casos en las DSP Gálicas (Atlante I, 1981, pág. 6), a las locales tardias datadas en los siglos Iv y vı d. C. de la zona de Rávena (Maioli, 1983, págs. 87 a 112), o las identificadas como "others late Roman slip wares» en la Schola Praecorum de Roma datadas en el siglo vı d. C. (Whitehouse et alii, 1982, págs. 57 y 63 y 1985, pág. 175).

${ }^{10}$ Es corriente asociar formas de las producciones locales tardias de sigillata hispánica a producciones galas. Larrén (1998, pág. 56), por poner un ejemplo, habla de la terra sigillata de imitación paleocristiana en su estudio de los materiales cerámicos de la Cabeza, Navasangil, Ávila. Molina mismo, al comentar los análisis que efectuó sobre sigillatas paleocristianas de Cástulo, afirma: «Creemos que los resultados de estos análisis apoyan aún más nuestra idea de una fabricación local de la sigillata paleocristiana de Cástulo, proceso que se inicia a través de la imitación de los tipos fabricados en los centros de producción franceses, llegando a la creación de tipos y decoraciones originales propios de los alfares castulonenses» (Molina, 1975, pág. 1013). En este mismo sentido se inclina Caballero aunque indicando: "sin que ello suponga, desde luego una renuncia total a la tradición "hispánica» y al sustrato de las claras D» (Caballero, 1989, pág. 86), es decir, a una posible asociación de algunas de estas producciones tardias a formas norteafricanas e hispánicas. No nos extraña, en cierta medida, esta asociación mayoritariamente gala; no nos podemos olvidar que la presencia cada vez más acusada a partir de fines del siglo ıv d. C. de producciones gálicas en Hispania, en especial en el ámbito mediterráneo con cerámicas de procedencia mayoritaria de la zona del Languedoc (ponemos como ejemplos el yacimiento de Vila-romá, en Tarragona (T'EDA, 1989) y el de Sa Mesquida (Orfila, 1989) en Mallorca), documentándose también en la Península producciones de DSP atlánticas, en especial en el norte de Hispania (Fernández Ochoa, C.; Garcia, P; Uscatescu, A, 1992).
} 
Pasta bastante depurada, de consistencia dura y compacta, escamosa, y con un aspecto parecido a las sigillatas claras o hispánicas tardias, como se apunta en la publicación de Cerro Maquiz (Arteaga; Blech, 1985 pág. 170). Presentan en algunas ocasiones particulas que pueden llegar a tener hasta varios milimetros de grosor; el color va entre anaranjado y rojizo, a ocre tirando a marrón y grisáceo, tonalidades que pueden presentarse a la vez sobre una misma pieza, lo que le confiere un aspecto no uniforme. El barniz es mas bien mate y suele tener el mismo tono y coloración que la pasta; puede que en ocasiones tengamos que hablar de una especie de engobe más que de barniz, en otras ocasiones casi ha desaparecido el tratamiento externo de las piezas, que tanto puede ser por la mala calidad del mismo, como consecuencia de los procesos post-deposicionales que han sufrido las mismas.

En cuanto a la cocción, Molina (1975) y Blázquez (1979) indican que en estas producciones fue de tipo reductor lo que les proporciona el color grisáceo, pero los colores descritos más arriba nos dan a entender que estariamos frente a una cocción final de tipo oxidante, apareciendo también en otras piezas una sección a modo de "sandwich", con un color oscuro en el interior y anaranjado en los exteriores, es decir, utilización de un ambiente reductor durante el proceso de calentamiento y mantenimiento durante un periodo de tiempo del mismo, y un ambiente oxidante durante la post-cocción o enfriamiento del horno. Estariamos frente a un alejamiento del proceso de cocción de las sigillatas clásicas en donde se utiliza la atmósfera oxidante para ambos casos.

En estos mismos términos define Ramallo (1984) las características de las cerámicas tardias de Begastri, concretamente las pertenecientes a los grupos dos, tres, cuatro y cinco "

Conviene destacar lo marcado que quedan las estrias del torno, como si fueran un motivo de decoración, llegando incluso a poderse interpretar como si estuviesen realizadas mediante el mismo buril que se utiliza en la decoración incisa más abajo descrita. Se suelen romper de manera laminar, casi nunca rectas, apareciendo en ocasiones unos desconchados, posiblemente producidos durante la cocción, en los que salta parte del barniz y de la pasta. En algunos casos no tienen un acabado perfecto o depurado, presentando rugosidades en los bordes, carenas o bases, en este mismo sentido estaria la asimetría de algunas piezas, al no tener la misma altura de un lado a otro. Generalmente la base de estas piezas o es plana o tiene un pie ligeramente diferenciado.

La decoración incisa burilada es una de las características que mejor diferencian estas producciones locales hispánicas de otras, repitiéndose triángulos, rombos o formas ovales $\mathrm{u}$ oblongas, tanto en horizontal como en vertical, formando franjas alrededor del borde, en el cuerpo (tanto en el interior como en el exterior), como sobre el fondo de las piezas. Estos motivos se pueden presentar combinados sobre un mismo objeto, pudiendo aparecer el mismo motivo en diferentes tamaños. Muy esporádicamente puede aparecer decoración impresa, como las que aquí presentamos sobre una pieza de la forma 4 (fig. 4 ) a modo de círculos, y sobre otra de la forma 5 (fig. 4) en la que aparecen unas palmetas. En algunas ocasiones y en especial sobre los cuencos TSHTM 1 aparece, a modo de decoración, una franja de unos dos o tres centímetros de color ceniza sobre el borde exterior, que puede aparecer en otras formas, como la 9.

"De las piezas que aparecen en las figuras de este artículo, sólo ponemos en duda la pertenencia a las producciones de TSHTM que presentamos la pieza de la figura 3 identificada con el número 30 , con forma no asociada a tipologías conocidas y decoración estampíllada que, como Ramallo indica, puede asemejarse a alguna del Cancho del Concesionario publicada por Caballero en 1975 (Ramallo, 1984, 78). 
Las posibles diferencias de tipo regional que Molina, Huertas, Ocaña (1980) indican en cuanto a una mejor calidad de las producciones paleocristianas procedentes de Cástulo en relación a las localizadas en la zona de Cerro del Cortijo del Molino del Tercio (Moraleda de Zafayona, Granada), más al sur, no creemos se pueda sostener. Piezas de diversas calidades se localizan indistintamente por todo el ámbito geográfico que abarca la dispersión hasta ahora conocida de las TSHTM. No obstante no descartamos la posibilidad de la existencia de varios centros productores como parece comprobarse desde el punto de vista de una observación macroscópica, en cuanto a compónentes de las pastas y barnices de estas cerámicas, apreciándose este hecho sobre materiales procedentes de un mismo yacimiento.

\section{DISPERSIÓN GEOGRÁFICA}

Con los datos que hasta ahora tenemos podemos presentar un ámbito geográfico de dispersión de estas producciones básicamente interior, como se aprecia en el mapa. Se documenta una mayor intensidad de hallazgos en las actuales provincias de Ciudad Real, Jaén, y Granada, parte de Almería y Málaga, documentándose también en las de Cuenca, Córdoba, Murcia y puede que hasta la altura de Madrid ${ }^{12}$. En el estudio de cada una de las formas de la tipologia de TSHTM que presentamos aqui aparecen citados yacimientos en los cuales se han identificado las piezas de estas producciones ${ }^{13}$.

12 No hemos podido obtener información referente a la zona de Albacete, ni más hacia occidente como puede ser la provincia de Sevilla, zonas en las que no creemos errar al pensar en la posibilidad de la localización de piezas de estas producciones en futuras investigaciones, de hecho las piezas identificadas como "sigillé dite tripolitaine» en Belo (Bourgeois; Mayet, 1991, pág. 12) pueden ser producciones de este tipo. Al mismo tiempo también queremos indicar las dudas que tenemos referente a la línea que pueda marcar la diferencia entre las producciones locales tardias de vajilla septentrionales de las meridionales, linea que seguramente podriamos mejor denominar como franja; no olvidemos la identificación de piezas de TSHT en el sur de la Península y la posibilidad de que puedan ir acompañadas de piezas de producciones locales septentrionales o viceversa; en este sentido consideramos que la variante de menor tamaño de la forma número 2 es más frecuente en yacimientos ubicados más al norte, como Oreto, Cancho del Confesionario o La Cabeza, de Navasangil, Ávila, publicados por Hortensia Larrén (1989) y relacionados por ella con las sigillatas paleocristianas de Cástulo, que en cierta manera ratifican el hecho de la localización de piezas más al norte, o de la asociación de formas en diferentes producciones de sigillatas tardias locales con formas de TSHT, asi como de la utilización común de decoración burilada.

${ }^{13}$ Queremos agradecer a todas las personas y entidades que nos han permitido consultar y utilizar datos obtenidos en sus investigaciones: A Lourdes Muñoz por los materiales de la villa de Bruñel, Quesada, base de este artículo; al Instituto Arqueológico Alemán de Madrid por consultar los materiales de Cerro Maquiz; Inocencio Blanco por los materiales de las prospecciones de Granátula (Ciudad Real); Esteban Moreno y Carmen García Bueno, por los materiales de Alcázar de San Juan y Valdepeñas (Ciudad Real); Pablo Casado por los materiales de Martos e Higuera de Calatrava (Jaén); Concha Choclán por los materiales depositados en el Museo de Linares, procedentes de Cástulo (Jaén); Dimas Martín, Dodes Camaliche y Esther Chávez por los materiales de la zona del Almanzora (Almeria); Pedro Aguayo por la pieza de Acinipo (Ronda); Rafael Hidalgo por los materiales de Cercadillas (Córdoba); Tomás Quesada y Encarna Motos por los materiales de la prospección de Jodar (Jaén). A Francisco Contreras por las prospecciones de Sierra Morena y a Fernando Molina por las del proyecto Millares. 
Esta dispersión de yacimientos puede dar pie a pensar que una cierta dificultad en el transporte para acceder hacia zonas más al interior de la Península de materiales de procedencia norteafricana, gálica u otras, y que sea esa la causa que origine una producción local de vajilla, aunque tampoco se pueden descartar causas comerciales, de encarecimiento del producto, etc. En Bruñel o en niveles de Cerro Maquiz, por poner algún ejemplo, la presencia de TSHTM es casi única, aunque también se ha documentado TSHTM en yacimientos como Las Pilas (Mojácar. Almeria), Córdoba o en Begastri (Cehegin, Murcia) lugares en donde llega masivamente la producción de vajilla norteafricana.

\section{TIPOLOGIA ${ }^{1+}$}

FORMA 1: Corresponde a las Rigoir 5 b y II de Molina (1975, pág. 1005), Blázquez (1979) y Molina et alii (1980), y al cuarto grupo de Ramallo (1984, pág. 76). Nosotros la consideramos como una Ritt. 8 (Orfila, en prensa).

Cuenco o bol de mediano tamaño de paredes redondeadas intuyéndose en algunas ocasiones una ligera carena con borde vuelto hacia el interior; alguna pieza puede presentar una inclinación hacia el exterior; labio redondeado o triangular, engrosado esporádicamente, que no suele diferenciarse. La base puede ser cóncava o con un pie ligeramente diferenciado. Presenta en muchas ocasiones una decoración burilada que puede presentarla en el borde como en el cuerpo y tanto en el interior como en el exterior, conjuntamente o en una de las partes mencionadas. En otras ocasiones y a modo de decoración podemos encontrar una franja de color ceniża, de unos 2 o 3 centímetros de altura en el borde exterior de las piezas.

La forma Ritt. 8 es frecuente en las producciones hispánicas tanto clásicas como tardías perdurando hasta el siglo Iv según Mezquíriz (Mezquíriz, 1985, pág. 146). En la zona de Castilla-León, en concreto en Clúnia (Peñalba de Castro), esta forma llega a monopolizar las producciones de los siglos $1 \mathrm{y}$ III (Tuset, 1991).

J. A. Paz documenta en la provincia de Zaragoza la forma Ritt. 8 en diversas variantes, llegando a medir un ejemplar de Turiaso, de un nivel del siglo iv d. C., $26 \mathrm{~cm}$. de diámetro y 10 de altura (Paz, 1991, pág. 57). En el teatro de Caesaraugusta se afilia una pieza de esta forma a los siglos v, vı d. C. (Paz, 1991, pág. 59); un dato a resaltar es la decoración que él denomina «en hueco», es decir burilada, como la Ritt. 8 núm. 389 de la fig. 71 .

Puede que en el siglo III d. C. esta pieza ya se fabricase, su presencia está documentada en otros yacimientos también del siglo iv y más adelante. En Cercadillas se ha documentado asociada a la forma 9 de TSHTM en un contexto del siglo $\mathrm{v} d$. C.

Ejemplos de esta forma se presentan en la fig. $1^{15}$.

Se han identificado piezas que se pueden adscribir a la forma 1 de TSHTM en los siguientes yacimientos:

Provincia de Ciudad Real: En Granátula de Calatrava en los yacimientos de Sedano y de La Peana; en Oreto y clasificadas como paleocristianas (Nieto et alii, 1980: fig. 52, núm. 250,

14 En Lisboa (Orfila, en prensa) ya se presentaron la mayoría de las formas aqui detalladas. Esperemos que una vez identificadas en otros yacimientos con mejores contextos, éstos aporten la documentación necesaria para confirmar o rebatir lo que se indica en este apartado.

15 Los dibujos originales de todas las figuras han sido realizados por Pilar Durán y Blas Medina. 


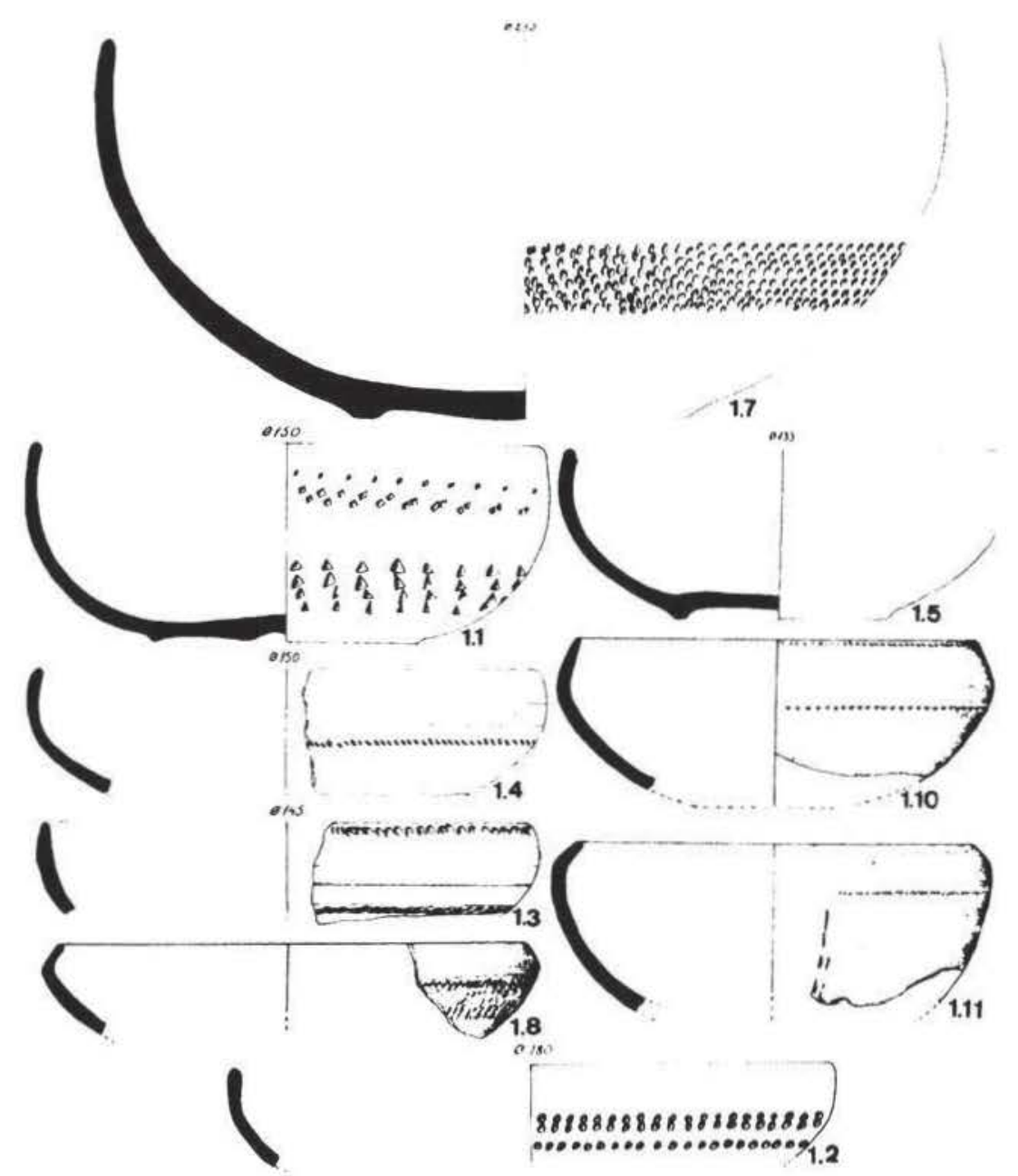

Figura 1.-1.1: Museo de Porcuna, $15 \mathrm{~cm}$. diám. boca; 1.2: Toloveo, Almería, $18 \mathrm{~cm}$. diám. boca; 1.3: Bruñel, Museo Provincial de Jaén, 14, $5 \mathrm{~cm}$. diám. boca; 1.4: Cástulo, Museo de Linares, $15 \mathrm{~cm}$. diám. boca; 1.5: Cástulo, Museo de Linares, 13,3 cm. diám. boca; 1.6: Cástulo, Museo de Linares, $25 \mathrm{~cm}$. diám. boca; 1.7: Cástulo II, patio J, fig. 115, núm. $41,14 \mathrm{~cm}$. diám. boca; 1.8: Cástulo II, patio J, fig. 115 , núm. $45,12 \mathrm{~cm}$. diám. boca; 1.9: Cástulo 11 , patio J, fig. 115 núm. $42,12 \mathrm{~cm}$. diám. boca.

pág. 159 , tabla 11 ; fig. 53 , núms. 252 a 254 , pág. 159 , tabla 11 ; fig. 64 , núm. 350 , pág. 162 , tabla 14; fig. 65 , núm. $351,353,355,365$, pág. 163, tabla 15; etc.). En la plaza de Alcázar de San Juan.

Provincia de Jaén: En Linares, yacimiento de Cástulo, además de las publicaciones en donde aparece caracterizada esta forma (Molina, 1975, pág. 1005) y en especial materiales procedentes de la villa urbana del Olivar (Blázquez, 1979), citaremos los trabajos de Urruela que cataloga como paleocristianas las piezas núms. 2 y 7 de la fig. 3 , adscritas a la forma II de Cástulo, procedentes del sondeo I (Blazquez, Contreras y Urruela, 1984, pág. 28); como sigillatas muy toscas y de mala calidad quedan catalogadas unas piezas del sondeo III (Blázquez, Contreras y Urruela, 1984, págs. 36 y 38 , fig 15 , núms. 4 y 7 ); del sondeo IV y dadas como sigillatas 
(formas Ritt. 8 y Drag. 37) podemos identificar de esta forma las siguientes piezas: fig. 18 núms. $3,6,9,10,12,14,16$ y 17 , de la fig. 19 los núms. $21,22,24,25,37$, y puede que el 23. Del sondeo VIII, la cata núm. 1, estrato $\mathrm{E} / 5$, también la pieza núm. 65 , dada como sigillata clara (Valiente, en Blázquez, Contreras y Urruela, 1984, pág. 149, fig. 7I, núm. 65).

En Arjona, en Cortijo del Puerco una pieza (Castro, 1986, fig. 23); en Jaén, en La VentaniIla (Castro, 1986, fig. 51). En Mengibar, yacimiento Cerro Maquiz. En Jodar, yacimiento Fontanarejo y yacimiento Barranco de Las Masavas. En Quesada, yacimiento Cortijo de Armas de Bruñel, una pieza procedente de las excavaciones realizadas en la villa.

Provincia de Granada: En Moraleda de Zafayona, yacimiento del Cortijo del Molino del Tercio, del corte 11, un fragmento de borde y pared decorado, dado como paleocristiana, forma Rigoir 6 (Molina et alii, 1980, núm. 10, pág. 258, fig. 24 núm. 10) y que nosotros consideramos como la forma 1 de TSHTM, en el corte 14 volvemos a identificar otro fragmento (Molina et alii, 1980, núm. 3, pág. 269, fig. 31 núm. 3).

Provincia de Almeria: Zona del Almanzora, yacimientos Toloveo, Cortijo Carrillo/los Merengallos y Las Pilas.

Provincia de Córdoba: En Córdoba, yacimiento Cercadillas, aparece esta forma en estrato del siglo $\vee \mathrm{d}$. C.

Provincia de Málaga: En Ronda, en el antiguo Acinipo se ha documentado una pieza de esta forma; en Cártama, en el yacimiento Manguarra y San José se ha identificado en el recinto $\mathrm{B} 1$, con el núm. 14 una pieza que se ha catalogado como posible paleocristiana (Serrano; de Luque, 1980, pág. 265, fig. 5 núm. 16).

Provincia de Cádiz: En Belo, la pieza identificada con el número 599 en la publicación de Bourgeois y Mayet (1911, pág. 312), con decoración biselada y catalogada como una producción tripolitana, podria ser muy bien una forma de TSHTM.

Comunidad autónoma de Murcia: En Cehegín, yacimiento de Begastri, piezas del número 18 al 27 (Ramallo, 1984).

FORMA 2: Corresponde a la forma Rigoir 18 Molina (1975, pág. 1006) y Blázquez (1979), a la forma 30 de Molina et alii (1980, pág. 278) y al tercer grupo de Ramallo (1984, pág. 75). Nosotros consideramos (Orfila, en prensa) esta forma semejante a la 37B de TSHT (Palol, Cortés, 1974, pág. 139; Mayet, 1984; López, 1985, págs. 140 a 141; Mezquíriz, 1983). Es una de las formas más frecuentes junto a las 1 y 9 .

Cuenco o bol con una carena muy marcada en el punto de contacto entre el borde, muy alargado, y el cuerpo, pie ligeramente señalado o casi inexistente. Podemos hablar de dos variantes, una de menor tamaño (fig. $2,2.1$ y 2.2) de unos $12 \mathrm{~cm}$. de diámetro boca, con la carena del cuerpo muy marcada y borde más curvo con el labio en su mayoría triangular, asociada a nuestra forma 8. Las piezas de la otra variante (fig. 2 del 2.3 al 2.7) de mayores dimensiones, unos 25 a $35 \mathrm{~cm}$. diámetro boca, con un borde más recto y labio un tanto redondeado sólo en algunas ocasiones diferenciado. Normalmente presenta decoración burilada con los típicos motivos romboidales, triangulares y ovales tanto en el interior como en el exterior.

Se podría pensar también que la variante de menor tamaño pudiera ser una evolución de la forma TSHTM 80 una forma por sí misma; consideramos más correcto darla como una variante de esta misma forma 2. Localizada principalmente en yacimientos ubicados mas al norte, como Oreto (Ciudad Real) y apareciendo en la meseta septentrional piezas muy parecidas, como en Navasangil (Ávila) (Larrén, 1989, fig. 4, núms. 6, 25, 84 o 123). 


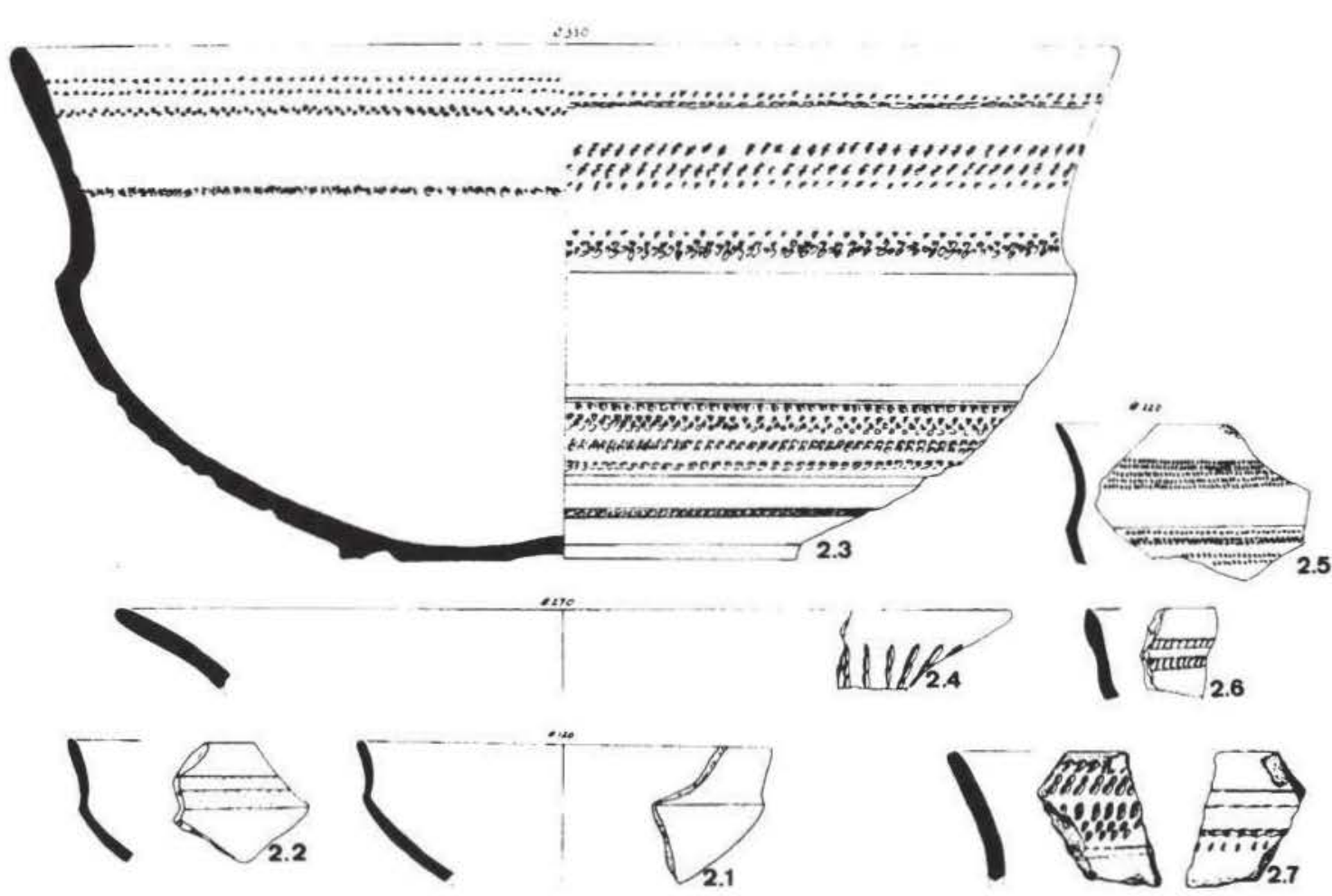

Figura 2.-2.1: Oreto I, fig. 64 , núm. $346,12 \mathrm{~cm}$. diám. boca; 2.2 : Oreto I, fig. 53 , núm. 256; 2.3: Bruñel, $33 \mathrm{~cm}$. diám. boca; 2.4: Cástulo, Museo de Linares, $27 \mathrm{~cm}$. diám. boca; 2.5: Begastri, núm. 13, $22 \mathrm{~cm}$. diám. boca; 2.6: Oreto I, fig. 53, núm. 255; 2.7: Cerro Franco. E. 1:3.

Una pieza con una carena parecida a esta forma 2, la variante de menor tamaño, fue hallada en Zaragoza catalogada como TSHT 11 de Palol recordando, como indica J. A. Paz, a la forma Rigoir 18, datada por estratigrafia en el siglo $\mathrm{v}$, otros perfiles de esta forma aparecen en otras figuras, destacaremos los de la núm. 70, con la decoración «en hueco», recordando la burilada de las TSHTM (Paz, 1991, pág. 99, fig. 28, núm. 177 y pág. 103).

Al considerarla como una 37 de TSHT tenemos que acogernos a la cronología que dan los autores citados más arriba a la misma.

Ejemplos de esta forma se presentan en la fig. 2 .

Se han identificado piezas que se pueden adscribir a la forma 2 de TSHTM en los siguientes yacimientos:

Provincia de Ciudad Real: En Granátula de Calatrava, yacimiento Oreto, pertenecientes a esta forma 2 de TSHTM, clasificadas como paleocristianas (Nieto et alii, 1980: fig. 53, núms. 255, 256 y 257 , pág. 159 , tabla 11 cortes K.10D, A y D respectivamente; fig. 64 , núms. 346 a 349 , pág. 162 , tabla 14 cortes $\mathrm{K} .10 \mathrm{~B}$; fig. 65 , núms. 358 a 365 , pág. 163 , tabla 15 cortes $\mathrm{K} .10 \mathrm{~A}$, B y C). En la plaza de Alcázar de San Juan. En Valdepeñas, yacimiento San Miguel.

Provincia de Jaén: Cástulo: Materiales procedentes de la villa urbana del Olivar (Blázquez, 1979), Urruela cita como paleocristianas la pieza núm. 3 de la fig. 3 , procedente del sondeo I (Blázquez, Contreras y Urruela, 1984, pág. 18), puede que la núm. 12 también lo sea, 
pero estaría la figura girada. En Arjona, yacimiento El Ardón, una pieza (Castro, 1986, fig. 16). En Higuera de Calatrava, yacimiento Cortijo del Cerro Franco, aparecen también fragmentos en Los Cuartos. En Mengibar, yacimiento Cerro Maquiz. En Jodar, yacimiento Fontanarejo. En Quesada, yacimiento Cortijo Plaza de Armas, Bruñel, varias piezas, entre ellas una con el perfil completo, procedentes de las excavaciones realizadas en la villa.

Provincia de Granada: En Moraleda de Zafayona, yacimiento Cortijo del Molino del Tercio, corte 1 un fragmento de borde decorado, dado como paleocristiana, forma Rigoir 18 (Molina et alii, 1980, núm. 2, pág. 233, fig. 7 núm. 4), corte 6 un borde decorado dado como paleocristiana forma Rigoir 18 (Molina et alii, 1980, núm. 2, pág. 244, fig. 15, núm. 2), corte 11 un borde y pared decorado, dado como paleocristiana, forma Rigoir 18 (Molina et alii, 1980, núm. 7, pág. 258, fig. 24, núm. 7), corte 14 (Molina et alii, 1980, núm. 5, pág. 269, fig. 31, núm. 5). En Illora, yacimientos Cortijo de los Yeros, núm. 138 y Cerro de la Barema, núm. 400.

Provincia de Cádiz: En Belo, las piezas identificadas con los números 597 y 598 en la publicación de Bourgeois y Mayet (1911, pág. 312), catalogadas dentro de una producción tripolitana, podría ser muy bien una forma de TSHTM.

Comunidad autónoma de Murcia: En Cehegín, yacimiento Begastri piezas del número 13 al 17 (Ramallo, 1984, pág. 75).

FORMA 3. Corresponde a la forma I de Molina (1975, pág. 1006) y Blázquez (1979) y a las formas 20,21 y puede que 32 de Molina et alii de 1980 (1980, pág. 278). Nosotros la consideramos (Orfila, en prensa) como una Lamb. 58 Hayes 80 (Atlante, 1981, pág. 104).

Pátera o fuente de escasa profundidad, con el borde vuelto hacia el exterior y con el labio redondeado sin diferenciar. La parte superior de la pared es recta exvasada, curvándose en su tercio inferior al unirse con el fondo, que es generalmente plano y que, a veces, presenta una acanaladura que configura un falso pie. Puede presentar decoración burilada en las paredes, tanto interior como exterior, además de en el fondo. En algunas ocasiones es dificultoso discernir entre la forma 3 y la 2 variante de mayor tamaño, si se tiene un fragmento de reducidas dimensiones de la zona del labio.

Al considerarla como una Hayes 80 tenemos que acogernos a la cronología que se da a la misma en las producciones. Datada inicialmente entre el 450 y el 500 por Hayes $(1972,128)$, su cronologia ha sido rebajada a la luz de los datos ofrecidos por la estratigrafia de Cartago y esta forma está ya bien documentada a inicios del siglo $\mathrm{v}$, así como en un contexto del 360 al 440 (Atlante, 1981, pág. 104).

Ejemplos de esta forma se presentan en la fig. 3 .

Se han identificado piezas que se pueden adscribir a la forma 3 de TSHTM en los siguientes yacimientos:

Provincia de Ciudad Real: En Granátula, yacimiento de Sedano. En Alcázar de San Juan.

Provincia de Jaén: En Linares, Cástulo, materiales procedentes de la villa urbana del Olivar (Blázquez, 1979). En Mengibar, yacimiento Cerro Maquiz. En Higuera de Arjona, Los Artesones, una pieza (Castro, 1986, fig. 50). En Higuera de Calatrava, yacimiento Cortijo del Cerro Franco aparecen varios fragmentos. En Jodar en los yacimientos Hornillos Bajos, Cerrillo de las Rojas, Barranco de Las Masavas. En Quesada, yacimiento Cortijo Plaza de Armas de Bruñel, varias piezas procedentes de las excavaciones realizadas en la villa.

Provincia de Granada: En Moraleda de Zafayona, yacimiento del Cortijo del Molino del 


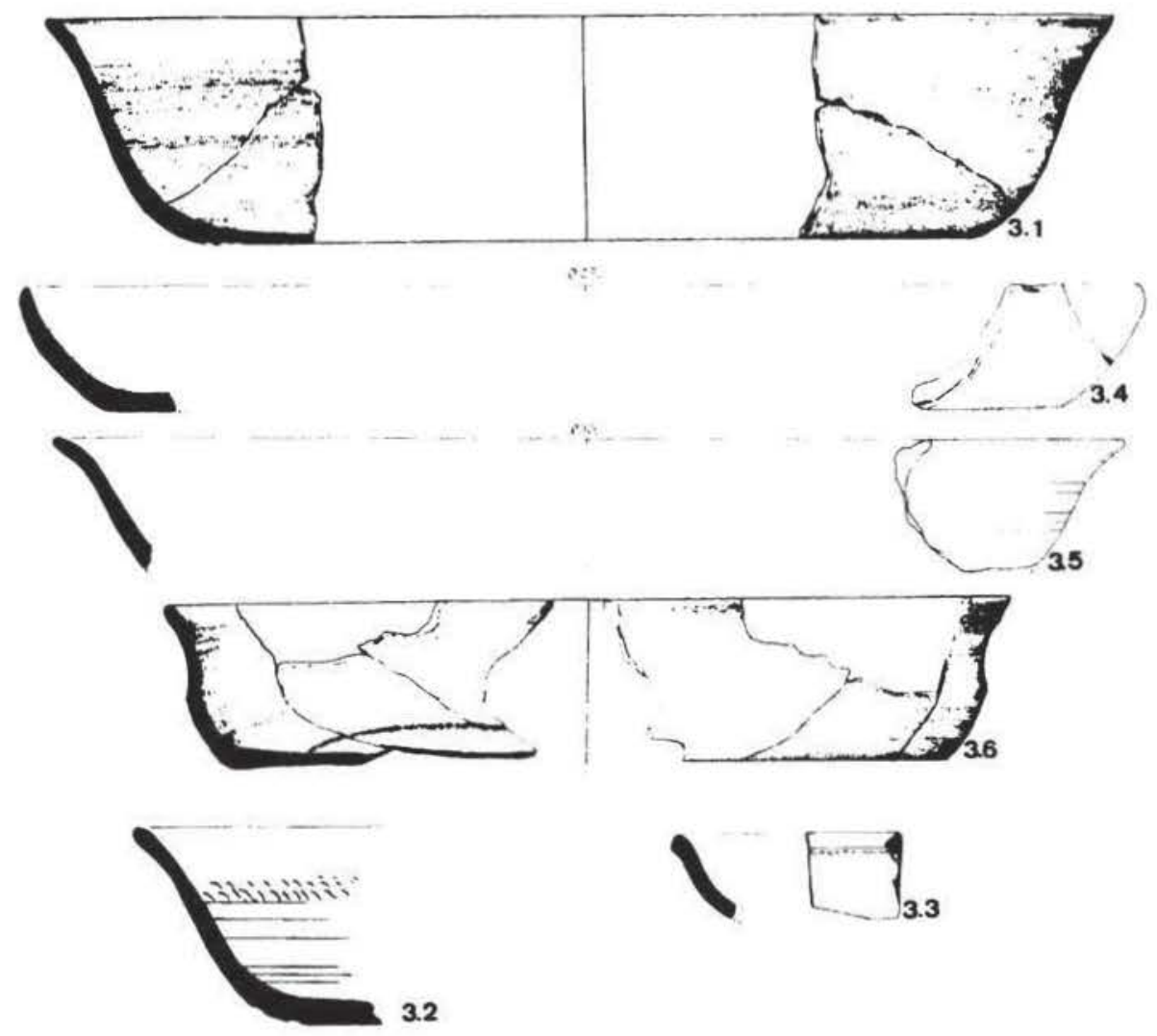

Figura 3.-3.1: Cástulo II, patio J, fig. 117, núm. 58, $30 \mathrm{~cm}$. diám. boca; 3.2: Bruñel; 3.3: Los Cuartos; 3.4: Cerro Franco; 3.5: Barranco de las Masavas, $30 \mathrm{~cm}$. diám. boca; 3.6: Cástulo II, ambiente F, fig. 92 núm. $21,24 \mathrm{~cm}$. diám. boca. E. 1:3.

Tercio, del corte 8, un fragmento de base decorado, dado como paleocristiana (Molina et alii, núm. 6, pág. 253, fig. 19, núm. 6).

Provincia de Cuenca: Yacimiento de Segóbriga los fragmentos 43, 44 y 45 catalogadas como imitaciones locales de cerámicas vulgares, pertenecen a la forma 3 de TSHTM (Losada; Donoso, 1965 , pág. 30 , fig. 12 , núms $5,6,7$ ).

FORMA 4. Podría corresponder a la forma Rigoir 1 de Molina (1975, pág. 1005) y Blázquez (Blázquez, 1979) ${ }^{16}$. Nosotros la consideramos semejante a la Lamboglia 51 , Hayes 59 , según las variantes. (Orfila, en prensa), aunque por la curvatura que puede llegar a tener la parte de la pared, podría recordar la Hayes 67.

Plato de paredes convexas exvasadas, con borde diferenciado horizontal o ligeramente inclinado hacia el interior, a modo de visera. El fondo es plano, pudiendo presentar, en ocasio-

${ }^{16}$ En Lisboa (Orfila, en prensa) indicamos que esta forma se podria asociar a la forma Rigoir 3 de Molina (1975) y Blázquez (1979), pero realmente la tenemos que asociar a la formas Rigoir 1 de la tipología de «Paleocristianas de Cástulo». 
nes, una acanaladura a modo de pie atrofiado. Curiosamente sólo hemos documentado decoración impresa realizada con un punzón realizada sobre piezas de esta forma (fig. 4).

La forma Rigoir 1 aparece en el Atlante (Atlante 1, 1981, pág. 6) como variante de la Drag. 51 y se relaciona con la forma Lamb. 51/Hayes 59. La forma hispánica tardia 4 aparecida en Pedrosa de la Vega (Palol; Cortés, 1974, págs. 124 a 127, fig. 37), localizada también en Mérida y en Conímbriga (Mayet 1984, pl. CCXLI a CCXLIV), se interpreta como una imitación de la forma H. 59 (Mayet, 1984, págs. 253 a 254). También se puede relacionar con la forma A.I de Caballero (1989, pág. 92) y que este autor asocia a la forma Rigoir 3 de Molina y Blázquez. En Cuenca en el yacimiento de Valeria, una pieza identificada como TSH forma 4 con decoración a ruedecilla recuerda esta forma que estamos describiendo aqui (SánchezLafuente, 1985, pág. 159, fig. 54, núm. 77).

Al considerarla como una Hayes 59 tenemos que acogernos a la datación que se da a la misma en las producciones norteafricanas. La cronología propuesta por Hayes para esta forma se sitúa entre el 320 al 400/420. La aparición en el vertedero de Vila-roma (Tarragona) reafirma su presencia en contextos de primera mitad del siglo v (TED'A, 1989). La Hayes 67 ha sido datada entre los años 360 y 470 , aunque se ha documentado también en un contexto del siglo Vı en Karanis (Atlante, 1981, pág. 89).

Ejemplos de esta forma se presentan en la fig. 4.

Se han identificado piezas que se pueden adscribir a la forma 4 de TSHTM en los siguientes yacimientos:

Provincia de Ciudad Real: En Granátula de Calatrava, Oreto (Nieto et alii, 1980: fig. 53, núm. 259 , pág. 159 , tabla 11 cortes $\mathrm{K} .10 \mathrm{~A}$ y fig. 66 , núm. 375 , tabla 15 corte $\mathrm{K} .10 \mathrm{~B}$ ).

Provincia de Jaén: En Linares, Cástulo, materiales procedentes de la villa urbana del Olivar (Blazquez, 1979). En Mengibar, yacimiento Cerro Maquiz. En Quesada, yacimiento Cortijo Plaza de Armas de Bruñel, una pieza procedente de las excavaciones realizadas en la villa.

Provincia de Cuenca: En Valeria, posiblemente se pueda considerar como una TSHTM 4 una pieza de este yacimiento (Sánchez-Lafuente, 1985, pág. 136, fig. 40, núms. 210 y 211), catalogada allí como Hispánica 4.

FORMA 5. No podemos asociar esta forma a ninguna de las presentadas por Molina y Blázquez (Molina, 1975; Blázquez, 1979); nosotros la consideramos semejante a la Lamboglia 57 y Hayes 73B, según las variantes (Orfila, en prensa).

Copa de borde diferenciado horizontal o ligeramente inclinado hacia arriba, liso o con una o dos acanaladuras, el labio está engrosado y las paredes suelen ser convexas exvasadas, tiene un pequeño pie anular diferenciado. Presenta una decoración impresa con punzón en un ejemplar a modo de hoja o palmera (fig. 4).

Aunque queda bastante clara la asociación a esta producción norteafricana, no podemos olvidar la semejanza a la forma 8 de la TSHT (Palol; Cortés, 1974, fig. 42) que tiene ciertas reminiscencias de la forma 5 de TSH (Mezquíriz, 1961), forma que se produjo en Andújar (Roca, 1976).

Al considerarla como una Hayes 73 tenemos que acogernos a la cronología que se da a la misma en las producciones norteafricanas, datadas entre los años 420 y 475 , según Hayes (Atlante 1981, pág. 72).

Ejemplos de esta forma se presentan en la fig. 4 . 


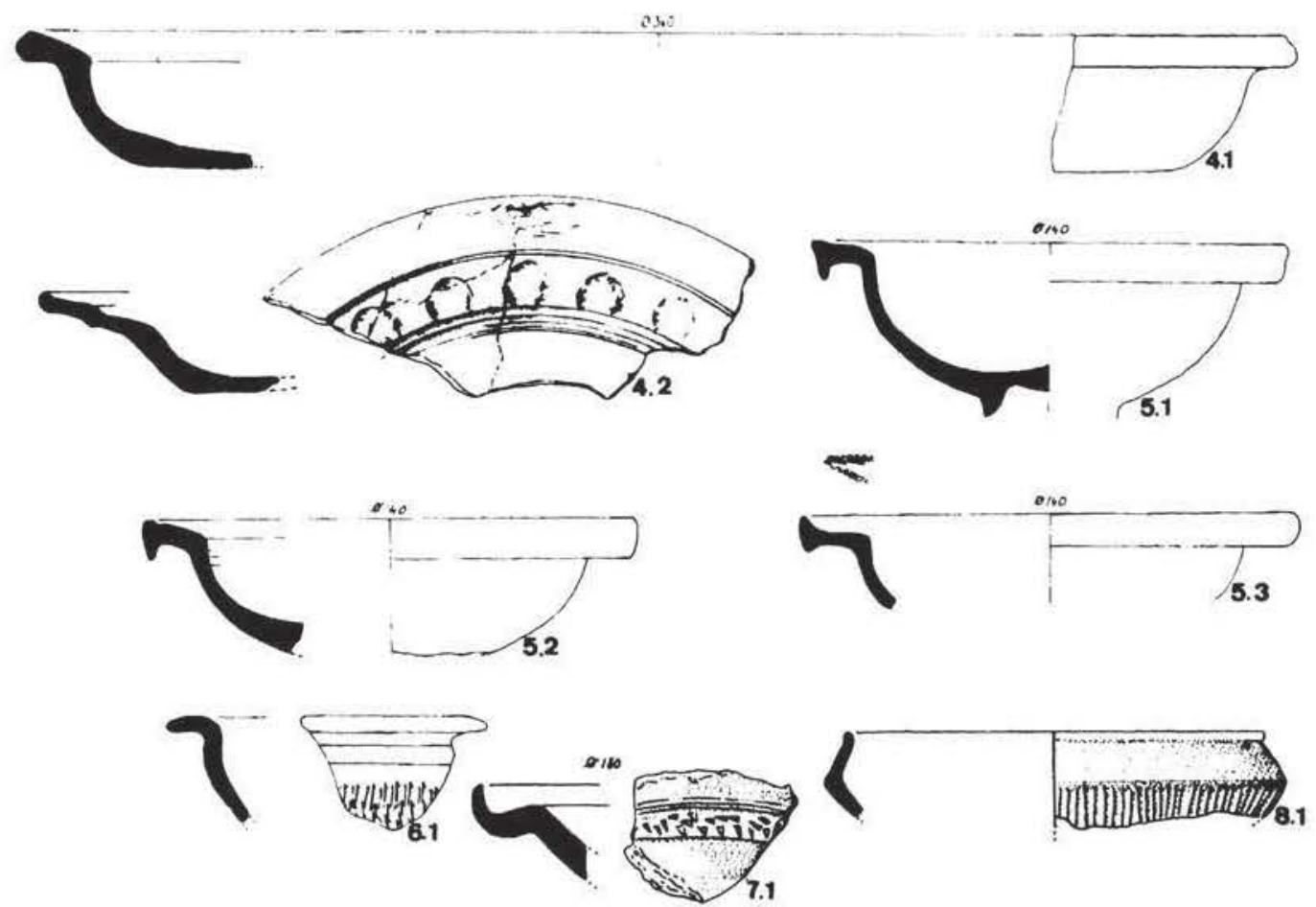

Figura 4.-4.1: Bruñel, $36 \mathrm{~cm}$. diám. boca; 4.2: Cástulo II, patio J, fig. 116 núm. $36,22 \mathrm{~cm}$. diám. boca. 5.1: Bruñel, $14 \mathrm{~cm}$. diám. boca; 5.2 : Bruñel, $14 \mathrm{~cm}$. diám. boca; 5.3: Cástulo, Museo de Linares, $14 \mathrm{~cm}$. diám. boca. 6.1: Bruñel. 7.1: Cástulo II, ambiente F, fig. 93 núm. $26,18 \mathrm{~cm}$. diám. boca. 8.1 : Cástulo II, ambiente F, fig. 93 núm. $29,12 \mathrm{~cm}$. diám. boca. E. 1:3.

Se han identificado piezas que se pueden adscribir a la forma 5 de TSHTM en los siguientes yacimientos:

Provincia de Jaén: En Quesada, yacimiento Cortijo Plaza de Armas en Bruñel, dos piezas procedentes de las excavaciones realizadas en la villa.

FORMA 6. Dentro de la tipología de Molina (1975, pág. 1005) y Blázquez (1979) la relacionaríamos con la forma Rigoir $3 \mathrm{~b}$ que ellos asocian a la Drag. 35. De esta forma clásica (Drag. 35) evolucionó a la Rigoir 3b (Atlante, 1981, pág. 6). Nosotros la consideramos semejante a la Lamboglia 35 y Hayes 44 , según las variantes. (Orfila, en prensa.)

Copa o cuenco de borde vuelto al exterior y paredes curvas. Presenta, en ocasiones, decoración burilada en la cara externa.

Se puede relacionar con el cuenco semiesférico, forma B.6 de las cerámicas de «época visigoda y postvisigoda", procedente de Cancho del Confesionario, Manzanares el Real (Madrid), dada como una posible variante de la forma II de Molina y catalogada en el grupo meridional de decoración burilada (Caballero, 1989, pág. 94).

Una forma parecida y definida como Drag. 35 es la presentada por J. A. Paz, con paredes mas gruesas, pie casi desaparecido, diámetro entre 10 y $13 \mathrm{cms}$., llegando su cronología hasta el siglo IV d. C. (Paz, 1991, pág. 63). 
Al considerarla como una Lamb. 35 , Hayes 44 tenemos que acogernos a la cronología que se da a la misma en las producciones norteafricanas datadas desde mediados del siglo III hasta finales del iv (Atlante, 1981, pág. 70).

Ejemplos de esta forma se presentan en la fig. 4.

Se han identificado piezas que se pueden adscribir a la forma 6 de TSHTM en los siguientes yacimientos:

Provincia de Ciudad Real: En Granátula de Calatrava, Oreto, puede que lo sea una pieza dada como paredes finas (Nieto et alii, 1980: fig. 56, núm. 287, pág. 160 , tabla 12 cortes K.10 A). En Alcázar de San Juan.

Provincia de Jaén: En Linares, yacimiento de Cástulo, materiales procedentes de la villa urbana del Olivar (Blázquez, 1979). En Quesada, yacimiento Cortijo Plaza de Armas de Bruñel.

Provincia de Córdoba: En Córdoba, en el yacimiento de Cercadillas aparece esta forma en un estrato del siglo $\mathrm{v} d$. C.

FORMA 7. Dentro de la tipología de Molina (1975) y Blázquez (1979) no la podemos relacionar con ninguna forma, aunque está catalogada una pieza con un perfil semejante al de la forma aquí descrita, TSHTM 7, como paleocristiana en Cástulo II (Blázquez, 1979, pág. 161). Pequeño bol de borde curvado y labio triangular vertical. Presenta decoración burilada. Puede relacionarse con varias formas debido al pequeño tamaño del fragmento recogido, tanto a una Drag. 27, pero con decoración incisa exterior, como al borde de las formas Drag. 44, suficientemente representadas dentro del repertorio de sigillatas hispánicas.

Es difícil dar una cronología individualizada a esta forma.

Ejemplos de esta forma se presentan en la fig. 4.

Se han identificado piezas que se pueden adscribir a la forma 7 de TSHTM en los siguientes yacimientos:

Provincia de Jaén: En Linares, Cástulo. En Jodar, yacimiento Fontanarejo.

FORMA 8. Corresponde a la forma III de Molina (1975, pág. 1007) y Blázquez (1979) y a la forma 1 de Molina et alii (1980, pág. 278). También a la forma B.1 y B.2 de Caballero (1989, pág. 93).

Vasito o cuenco de borde vuelto al exterior con labio redondeado ligeramente diferenciado, cuerpo de forma troncocónica. La podemos asociar a la variante de menor tamaño de nuestra forma 2.

Catalogada en Cancho del Confesionario, Manzanares el Real (Madrid), como un cuenco perteneciente a la forma $\mathrm{B}$ de las cerámicas de «época visigoda y postvisigoda» y que nosotros asociamos concretamente a las variantes B.1 y B.2, dada como forma evolucionada de Rig. 22 que a su vez habría evolucionado de la Rig. 18. Recuerda esta forma a la pieza procedente del yacimiento de Varea (Logroño), dada como forma de las producciones locales en cerámica común romana (Luezas; Saenz, 1989, pág. 177, fig. 83).

Es dificil dar una cronología individualizada a esta forma.

Ejemplos de esta forma se presentan en la fig. 4.

Se han identificado piezas que se pueden adscribir a la forma 8 de TSHTM en los siguientes yacimientos:

Provincia de Ciudad Real: En Granátula de Calatrava, Oreto, una pieza dada como paleocristiana (Nieto et alii, 1980: fig. 52, núm. 250, pág. 159, tabla 11 corte K.10 A). 


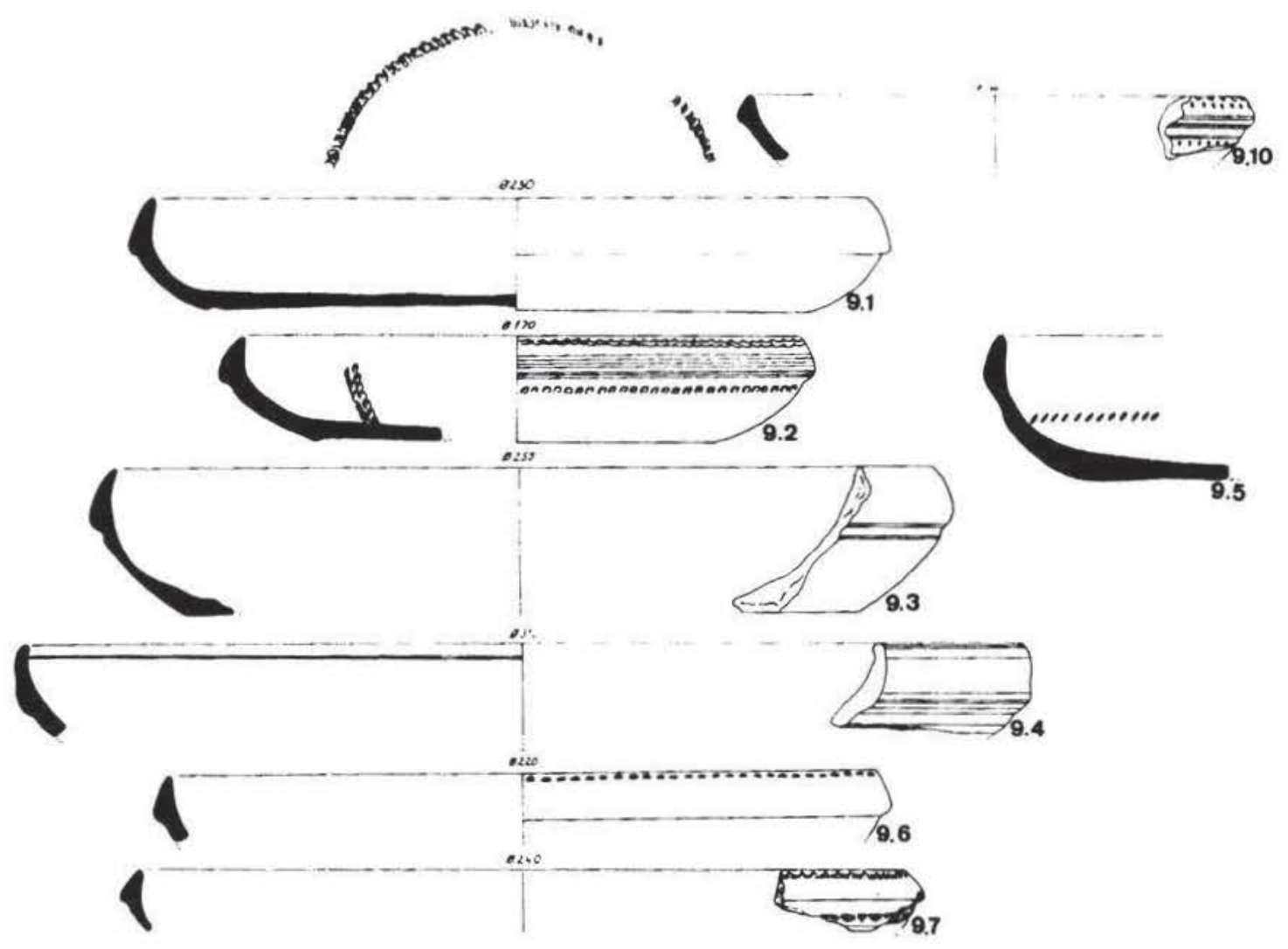

Figura 5.-9.1: Bruñel, $23 \mathrm{~cm}$. diám. boca; 9.2 : Bruñel, $17 \mathrm{~cm}$. diám. boca; 9.3: Bruñel, $25 \mathrm{~cm}$. diám. boca; 9.4: La Peana, $31 \mathrm{~cm}$. diám. boca; 9.5: Bruñel; 9.6: Toloveo, $22 \mathrm{~cm}$. diám. boca; 9.7: Illora, $24 \mathrm{~cm}$. diám. boca; 9.10: La Peana, $16 \mathrm{~cm}$. diám. boca. E. 1:3.

Provincia de Jaén: En Linares, Cástulo, materiales procedentes de la villa urbana del Olivar (Blázquez, 1979).

Provincia de Granada: En Moraleda de Zafayona, yacimiento Cortijo del Molino del Tercio (Molina et alii, 1980, pág. 278).

Provincia de Cuenca: Segóbriga, puede que la pieza catalogada como cerámica vulgar puedan identificarse con la forma 8 de TSHTM (Losada; Donoso, 1965, pág. 40, fig. 18, núm. 3).

Comunidad autónoma de Madrid: En Manzanares el Real, yacimiento de Cancho del Confesionario (Caballero, 1989, pág. 93).

FORMA 9. Corresponde a la forma Rigoir 8 de Molina (1975, pág. 1005) y Blázquez (1979), a la forma 5b de Molina et alii (1980, pág. 278) y al segundo grupo de Ramallo (1984, pág. 73). Nosotros la consideramos como una Hayes 61, Lamb. 53 (Orfila, en prensa).

Plato de paredes convexas exvasadas, con borde ligeramente diferenciado de sección triangular que puede ser ligeramente entrante, vertical o exvasado, dependiendo de las distintas variantes. El fondo es plano, presentando decoración burilada tanto en el labio, como en las paredes externas o en el fondo del mismo, a modo de decoración aparecen las estrias del torno muy marcadas, llegando incluso a poderse interpretar como realizadas mediante el mismo buril que se ha utilizado en la anterior decoración mencionada. 
Molina (1975) y Blázquez (1979) definen esta forma como un plato o cuenco de borde en almendra, muy frecuente en Cástulo y con bastantes variantes, derivado de las formas 53 y 55 de sigillata clara D. En Atlante se hace referencia a la imitación de esta forma en producción gálica a la forma Lamb. 60 bis (Atlante, 1981, pág. 6).

Evidentemente que esta forma, en esta posible producción del sur de Hispania, tiene unos claros reflejos de la norteafricana Hayes 61, Lamb. 53, con una serie de variantes que se pueden apreciar en la fig. 5, 6 y 7 .

Continuando con las comparaciones podríamos decir que se puede relacionar con la forma 2 de la TSHT (Palol; Cortés, 1974, pág. 123 a 125, fig. 36, núm. 32 a 34); Mayet la relaciona con la Hayes 61 (1984, pág. 255, pl. CCXLVIII), no nos extraña, por tanto, la semejanza en perfiles entre producciones septentrionales y meridionales.

Al considerarla como una Hayes 61 tenemos que acogernos a la cronologia que se da a la misma en las producciones norteafricanas datadas, según Hayes (1972), entre los años 325 y 450 siendo ligeramente más antigua la variante H. 61A (325 al 400/425), mientras que la variante H. 61B empezaria a producirse un poco más tarde que la anterior (380/390), perdurando hasta aproximadamente el año 450 (Atlante, 1981, pág. 70).

Ejemplos de esta forma se presentan en las figs. 5, 6 y 7.

Se han identificado piezas que se pueden adscribir a la forma 9 de TSHTM en los siguientes yacimientos:

Provincia de Ciudad Real: En Granátula, Oreto, una pieza dada como cerámica vulgar (Nieto et alii, 1980: fig. 42, núm. 134, pág. 154, tabla 6 corte K.10 B). Aparece también en los yacimientos de Sedano (un borde y una base decorados ambos) y La Peana. En Alcázar de San Juan y en Valdepeñas, yacimiento de San Miguel.

Provincia de Jaén: En Linares, Cástulo, materiales procedentes de la villa urbana del Olivar (Blázquez, 1979). Del sondeo III (Blázquez, Contreras y Urruela, 1984, pág. 36 y 38, fig 15, núm. 1) una pieza de esta forma dada como posible Drag. 29. En Arjona, en Cortijo del Puerco, una pieza (Castro, 1986, fig. 22) y en El Ardón (Castro, 1986, fig. 16). Puente del Rey, yacimiento El Calvete (Castro, 1986, fig. 46). En Higuera de Calatrava, yacimiento Cortijo del Cerro Franco, aparecen varios fragmentos de esta forma. En Martos, yacimientos Los Aljibes y Los Cuartos. En Mengibar, yacimiento Cerro Maquiz. En Jodar, en Fontanarejo y Cantaruela. En Quesada, yacimiento Cortijo Plaza de Armas de Bruñel, varias piezas, entre ellas dos enteras. En Úbeda, El Torreón fig. 3, dada como terra sigillata hispánica, forma 55 (Ruiz, Malpesa, 1982).

Provincia de Granada: En Moraleda de Zafayona, yacimiento Cortijo del Molino del Tercio, del corte 10, un fragmento de base decorado, dado ya como sigillata paleocristiana (Molina et alii, núm. 9, pág. 255, fig. 22, núm. 9). En Illora, yacimientos Cortijo de los Yeros, núms. 127 y 130 y Cerro de la Barema, núm. 102.

Provincia de Almería: Zona del Almanzora, yacimiento Toloveo. En Tabernas, yacimiento AL-TA 3.

Provincia de Córdoba: Córdoba, yacimiento Cercadillas, aparece esta forma en estrato del siglo $v$ d. C.

Provincia de Málaga: En Cártama, en el yacimiento de Manguarra y San José se ha identificado en el recinto $\mathrm{V}$ con el núm. 4 una pieza que se ha catalogado como sigillata clara, aunque indicando que recuerda a la forma Rigoir 8 , de $12 \mathrm{~cm}$. de diámetro (Serrano; de Luque, 1980, pág. 323, fig. 40 núm. 4). 


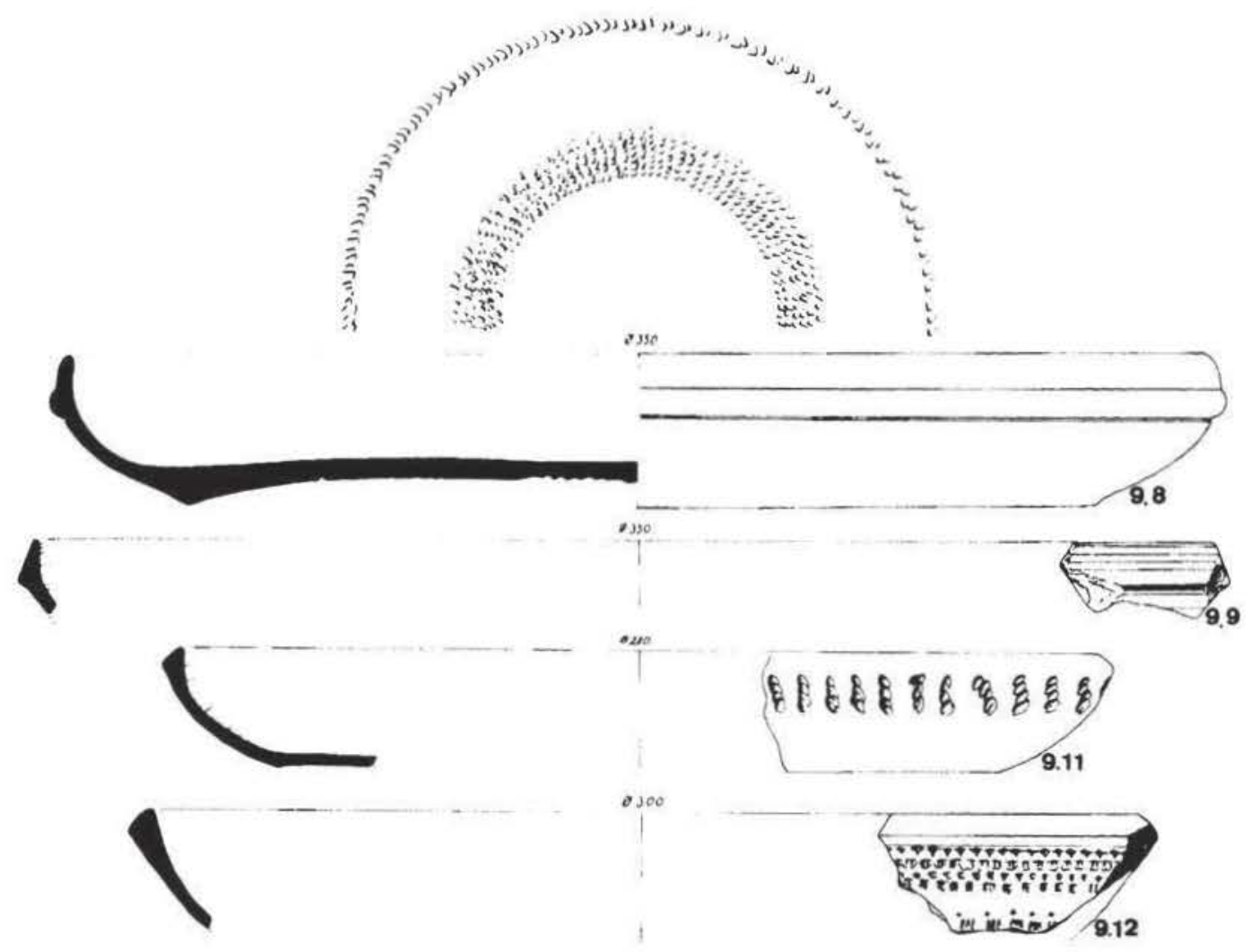

Figura 6,-9.8: Bruñel, $35 \mathrm{~cm}$. diám. boca; 9.9: Cerro Franco, $35 \mathrm{~cm}$. diám. boca; 9.11: Cástulo, Museo de Linares, $28 \mathrm{~cm}$. diám. boca; 9.12: Barranco de las Majavas, $30 \mathrm{~cm}$. diám. boca. E. 1:3.

Provincia de Cádiz: En Belo, la pieza identificada con el número 600 en la publicación de Bourgeois y Mayet (1911, pág. 312), con decoración biselada y catalogada como una producción tripolitana, podría ser muy bien una forma de TSHTM.

Provincia de Cuenca: Yacimiento de Valeria, una pieza identificada como forma inédita, de $25 \mathrm{~cm}$. de diámetro, con decoración a ruedecilla y acanaladuras, pasta beige anaranjada y barniz marrón bien conservado (Sánchez-Lafuente, 1985, pág. 138, fig. 41, núm. 220) que nosotros la podemos asociar a esta forma 9 .

Comunidad autónoma de Murcia: Cehegín, yacimiento de Begastri piezas del número 4 al 12 (Ramallo, 1984, pág. 73-74).

FORMA 10. Podemos considerar dentro de esta forma las piezas cerradas, jarras, identificadas con las formas IV y V de Molina (1975, pág. 1007) y Blázquez (1979, pág. 234) y las formas 35, 40 y 42 de Molina et alii (1980, págs. 278 y 279).

Es dificil dar una cronologia individualizada a esta forma.

Se han identificado piezas que se pueden adscribir a la forma 10 de TSHTM en los siguientes yacimientos: 
Provincia de Ciudad Real: En Granátula de Calatrava, yacimiento Sedano se ha identificado un fragmento amorfo decorado de una forma cerrada.

Provincia de Jaén: En Linares, Cástulo, materiales procedentes de la villa urbana del Olivar (Blázquez, 1979).

Provincia de Granada: En Moraleda de Zafayona, yacimiento Cortijo del Molino del Tercio, dentro de la tabla tipológica, números 35, 40 y 42 (Molina et alii, 1980, pág. 278 y 180).

Podrian pertenecen a estas producciones de TSHTM las piezas del 0.1 al 0.5 que presentamos en la figura 7.

\section{CONSIDERACIONES GENERALES}

A la hora de intentar dar un marco cronológico a estas producciones de sigillatas hispánicas tardias meridionales, éste tendria que ser básicamente los siglos iv y $\vee \mathrm{d}$. C., dataciones muy cercanas a las indicadas por Ramallo (1984, pág. 79), siempre desde un punto de vista provisional, a las cerámicas tardías de Begastri: entre la segunda mitad del siglo iv y la primera del vı. La presencia de una imitación de la Ritt. 8 podría indicar un inicio anterior de esta producción, difícil de precisar, pero que podriamos aventurarnos a señalar a finales

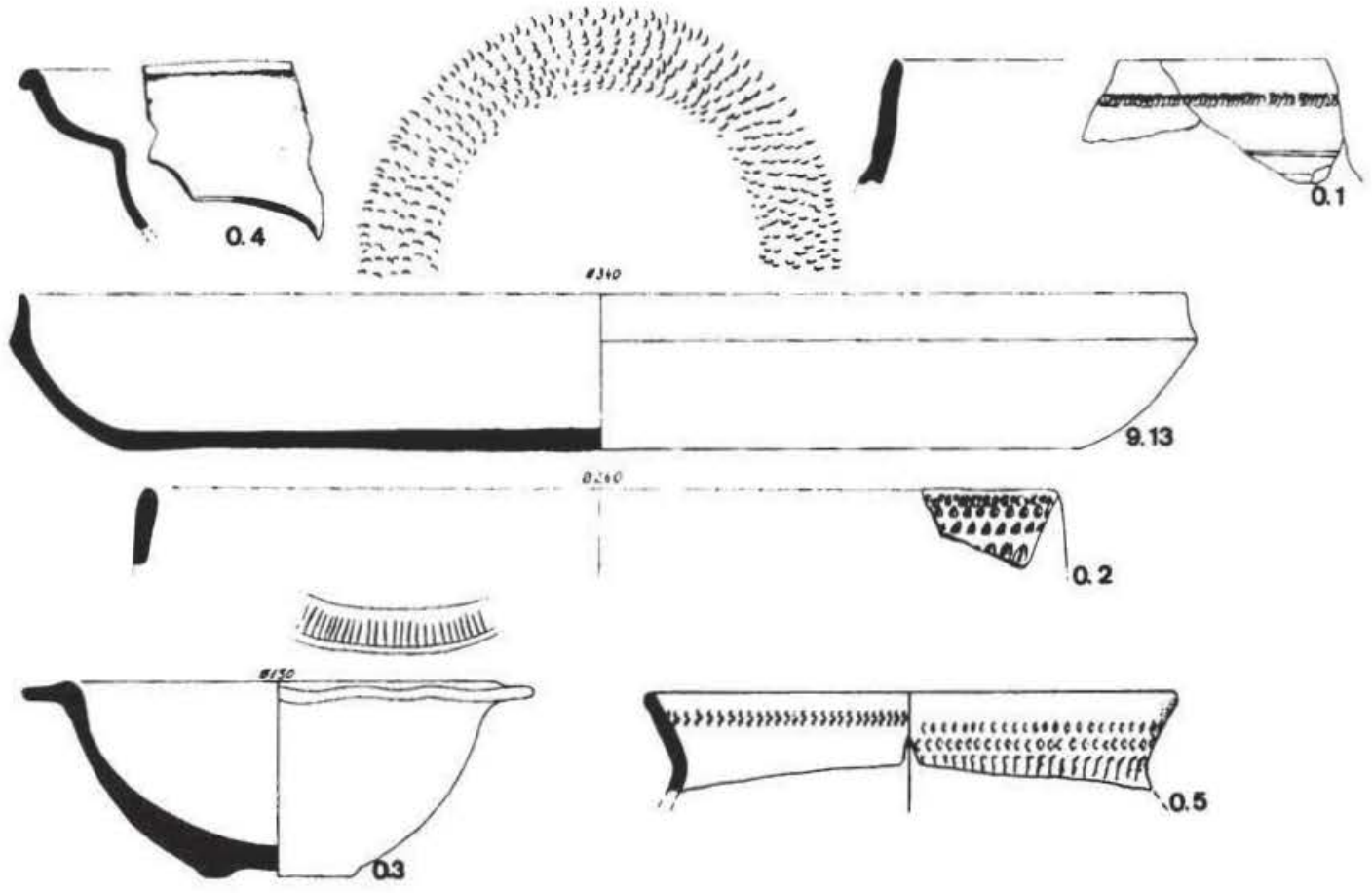

Figura 7. -9.13: Bruñel, $34 \mathrm{~cm}$. diám. boca; 0.1: Bruñel; 0.2 : Illora, $26 \mathrm{~cm}$. diám. boca; 0.3 : Cástulo, Museo de Linares.; 0.4: Cástulo II, ambiente J, fig. 118, núm. 70; 0.5: Cástulo II, ambiente F, fig. 93 núm. 31. E. 1:3. 
del siglo ॥ o ya en el III. Un dato a tener en cuenta es la estratigrafia del Sondeo V de Cástulo (Fernández, P. en Blázquez; Contreras; Urruela, 1984, págs. 116 a 118), en la que los materiales tienen una cronología entre mediados del siglo I d. C. (fase II), a inicios del II, sin que aparezca ningún fragmento que podamos identificar como TSHTM. En esta misma linea estarían los resultados de las excavaciones de las catas 3,4 y 5 del Sondeo IV del mismo Cástulo, con dataciones que llegan hasta incluso finales del siglo III d. C., y en las que no se han representado tampoco en las figuras ninguna pieza identificable como TSHTM (Artigas, Domínguez, Peña y Rodriguez, en Blázquez, Contreras y Urruela, 1984, pág. 232).

Dos problemas de investigación existen referentes a las TSHTM en la actualidad: $a$ ) Su localización mayoritaria en excavaciones antiguas con malas estratigrafias o su procedencia de prospecciones y, por tanto, sin una cronología documentada en contexto arqueológico fiable. En este sentido la futura publicación de la memoria de las excavaciones realizadas en el yacimientos de Cercadillas (Córdoba) posiblemente nos proporcione dataciones más precisas ya que se han contextualizado materiales de estas producciones (formas de TSHTM, 1, 9 y en menor cantidad la 6) en niveles del siglo $v$ d. C. ${ }^{17}$

b) La no identificación hasta la actualidad de ningún posible alfar de terra sigillata hispánica tardía meridional por lo que tampoco podemos aún diferenciar si se realizaron en un solo centro productor o, como pensamos en la actualidad, en varios, por eso solemos utilizar el término en plural: producciones de sigillata tardía meridional. Esa no identificación de alfares es la que no permite, por tanto, caracterizar analiticamente las piezas en este tipo de yacimientos. Tampoco se han realizado suficientes análisis ${ }^{1 \times}$ de este tipo de vajillas en lugares en principio receptores como para poder comparar con suficiente rigor sus características con otras producciones bien identificadas. Tenemos que sopesar también la rentabilidad de los posibles resultados de la analítica sobre piezas descontextualizadas, que es con lo que mayoritariamente contamos en la actualidad.

Consideramos también que las TSHTM son fruto de la continuidad de la tradición de fabricación de piezas de cerámica tan arraigada en la Península y en el Sur en especial (basta remontarnos a la época ibérica o alto imperial romana con la cantidad de producciones identificadas). En este sentido no creemos errar al pensar que en un futuro se puedan identificar piezas intermedias entre las sigillatas clásicas ${ }^{19}$ y las tardías, ya no sólo en el Sur de la Península, sino en general. Podriamos considerar como piezas intermedias entre las clásicas y las tardías las que presentan unos pies menos diferenciados o son de peor calidad en su acabado o

17 Agradecemos al equipo que dirige Rafael Hidalgo la información que nos han proporcionado.

is Se realizaron unos análisis a mediados de 1975 sobre piezas identificadas como Paleocristianas de Cástulo, extrayendo de los mismos la siguiente información: "Análisis por refracción de rayos X, realizada sobre sigillatas paleocristianas de Cástulo por los doctores Linares y Barahona. Se ha podido observar cómo la arcilla utilizada para la fabricación de la paleocristiana gris es muy semejante a la de la cerámica común romana. Por otra parte la arcilla de la sigillata hispánica es también muy similar a la de la sigillata paleocristiana anaranjada» (Molina, 1975, pág. 1013).

$19 \mathrm{Ya}$ hemos mencionado en la nota 2 que existe un salto entre la cronología final de las sigillatas clásicas, en el siglo ॥ d. C. y el inicio en el siglo ıv de las producciones de TSHT (Mezquiriz, 1983, pág. 136), como ya indicaba M. Roca en su artículo de 1981: «Lo que está claro es que en el sur de la Península no parece que se produzca sigillata después del siglo II» (1981, pág. 407). Evidentemente que estas dos autoras se refieren a las producciones de estas vajillas de sigillatas con los condicionantes que señalamos en la nota 8 . 


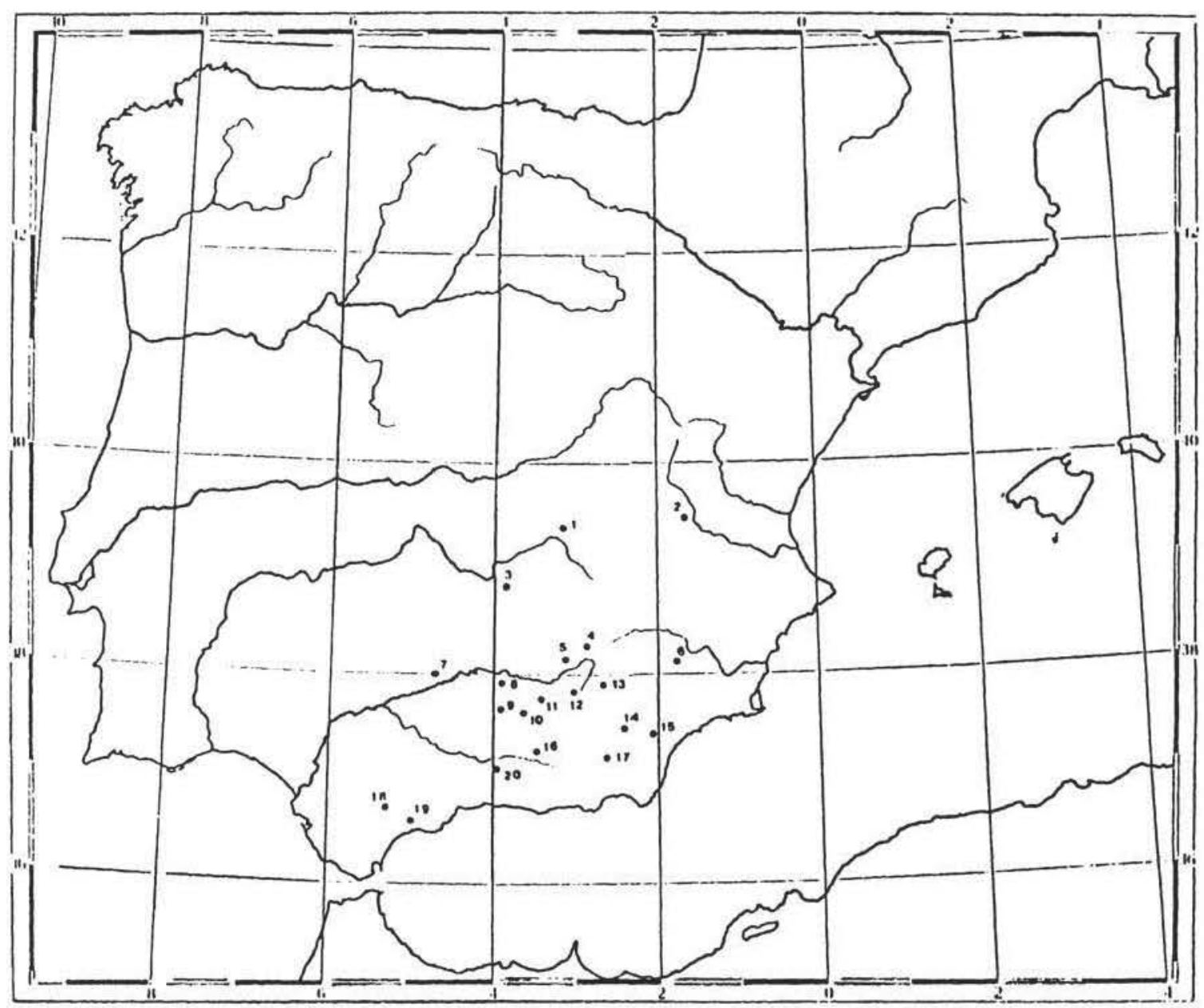

Figura 8.-1. Alcázar de San Juan; 2. Segobriga; 3. Oretum, Granátula de Calatrava; 4. Cástulo; 5. Baños de la Encina; 6. Cehegín; 7. Córdoba; 8. Porcuna; 9. Higuera de Calatrava; 10. Martos; 11. Cerro Maquiz; 12. Jodar; 13. Bruñel; 14. Galera; 15. Almanzora; 16. Granada; 17. Tabernas; 18. Acinipo, Ronda; 19. Cártama; 20. Moraleda de Zafayona.

en su barniz, llegando incluso a diferenciarse en algunos fragmentos un barniz interior «tipo clásico» y semejante al tardio meridional en el exterior ${ }^{20}$. Esperemos que ese enlace aparezca documentado en un futuro en alguna estratigrafia ${ }^{21}$.

20 Una pieza con estas características se ha localizado en prospección en el yacimiento de Cortijo del Cerro Franco (Higuera de Calatrava, Jaén).

21 La presencia en las excavaciones en Cercadillas (Córdoba) de materiales no sólo de TSHTM, dentro de un contexto del siglo IV-v d. C., también producciones anteriores a éstas, en cierta manera como enlace entre las sigillatas clásicas de los siglos i y $\mathrm{Il}, \mathrm{y}$ las del $\mathrm{iv}, \mathrm{v}$, al identificarse producciones datadas en el siglo III d. C., de los cuales esperamos su pronta publicación, creemos vendrán a corroborar 


\section{BIBLIOGRAFIA}

Atl.ante DE: Les formes (erramiques 1, 1981: Enciclopedia dell Arte Antica, Roma.

Artfagia, O.; Bı.f(H, M.; 1985: Excavaciones en el Cerro de Maquiz (Mengibar, Jaén,). Campaña de 1985. Anuario Arqueológico de Andalucia 11. Actividades sistemáticas, págs. 169-172, Sevilla.

Blazquez, J. M., 1979: Cástulo II, en Excavaciones Arqueologicas en España 105. Madrid.

Bl.azquez, J. M.; Contreras, R.; Urruruei.A, J. J.; 1984: Cástulo IV, en Excaiaciones Arqueológicas en España, 131, Madrid.

Blazquez, J. M.; Garcia-Gelabert M. P. ; Lopez, F.; 1985: Cástulo V, en Excavaciones arqueológicas en España, 140, Madrid.

Bourgeols, A.; Mayet, F., 1991: "Belo VI. Les sigillés. Fouilles de Belo", Collection de la Casa de Velázquez, Archéologie XIV.

Caballero Zorfid, L., 1970: Nuevos datos sobre cerámicas sigillatas hispánica, claras de tipo B y sigillata brillante, Trabajos de Prehistoria, 27, págs. 300-310, Madrid.

CABAllero Zoreda, L., 1982: Una muestra de cerámicas sigillatas claras e hispánicas tardias de Mérida, Homenaje a Saenz de Buruaga, págs. 177-200, Badajoz.

Caballero Zoreda, L., 1985: Hallazgo de un conjunto tardorromano en la calle Sur de Getafe (Madrid), Bol. del Museo Arqueológico Nacional, 3, págs. 97-127, Madrid.

Caballero Zoreda, L., 1989: Cerámicas de "época visigoda y postvisigoda» de las provincias de Cáceres, Madrid y Segovia, Boletin de Arqueologia Medieval, IIl, págs. 75 a 108, Madrid.

Caballero Zoreda, L., Argente Oliver, J. L., 1975: Cerámica paleocristiana, gris y anaranjada, producida en España, Trabajos de Prehistoria, 32, págs. 113-150, Madrid.

Caballero Zoreda, L.; Juan Tóvar, L. C., 1983/84: Terra sigillata hispánica brillante, Ampuries, 45-46. págs. 154-193, Barcelona.

Carrocera, E.; Requejo, O. 1989: Producciones cerámicas tardias en castros y villas asturianas, Boletín de Arqueologia Medieval 3, págs. 21-30, Madrid.

Castro López, M., 1986: Poblamiento e implantación rural en las Campiñas Occidentales del Alto Guadalquivir: siglos $\|$ a. C./ $v d$. C. . Memoria de Licenciatura, Universidad de Granada, Granada.

Cerrillo martin de Caceres, E.; Cerrillo Martin de Caceres, J., 1984/85: Acerca del origen de la producción local de cerámicas estampilladas del siglos $\mathrm{v} / \mathrm{v}$, Zephyrus $X X X V I I-X X X V I I I$, págs. 361370 , Salamanca.

Darton, A. 1972: Sigillée claire B de la vallée du Rhône, Rivista. di Studi. Liguri, XXXVIII, 2 pág. 137-189.

Desbats, A.; Pıcon, M., 1986: Sigillée claire B et «luisante»: classification et provenance, Figlina ,7, págs. $5-18$, Lyon.

Domergue, C., 1967: La mine antique de Diógenes (Ciudad Real), Melanges de la Casa de Velázquez, III, París.

Domergue, C., 1969: La campagne des fouilles 1966 à Bolonia (Cádiz), X Congreso Nacional de Arqueologia, Zaragoza.

la hipótesis de la continuidad de producción de cerámica fina en la Bética, enlazando con las TSHTM, ya más tardias. Agradecemos de nuevo la información proporcionada por Rafael Hidalgo y el equipo que dirige. En otras zonas de la Península Ibérica se han definido en este sentido, como ejemplo podemos referirnos a los «productos transicionales de terra sigillata hispánica a terra sigillata hispánica tardía» de los hornos de Belorado, en la cuenca del Duero, publicados por Pérez Rodríguez (1989, pág. 169), o las «sigillatas hispánicas intermedias» de la zona de Zaragoza, publicadas por Paz (1991), en este mismo campo tendriamos que nombrar también las «sigillatas hispánicas brillantes» definidas por Caballero y Juan en 1984 y datadas entre fines del siglo It hasta el siglo v d. C (Caballero y Juan, 1984, pág. 177). Ejemplos de continuidad de producción también se tiene en la Galia con la terra sigillata clara B definida por Lamboglia y posteriormente estudiada por Darton (1972), Vernhet (1977) o Desbats y Picon (1986), datada entre los años $140 / 160$ y $250 / 260$. 
Fernandez, C.; Garcia Diaz, P.; Uscatescu Barrón, A., 1992: Gijón en el período tardoantiguo: cerámicas importadas de las excavaciones de Cimadevilla, Archivo Español de Arqueologia, 65, págs. 105148, Madrid.

Hayes, J. W., 1972: Late Roman pottery, London.

Lambogil.ıA, N., 1954: Nuove osservazione sulla Terra Sigillata Chiara tipi «A e B» Rivista di Studi Liguri, XIV, Bordighera.

Lambocil.iA, N., 1963: Nuove osservazione sulla Terra Sigillata Chiara tipi "C e D» Rivista di Studi Liguri, XXIX, Bordighera.

Larrf́n, H., 1989: Materiales cerámicos de La Cabeza: Navasangil (Ávila), Boletín de Arqueologia Medieval, III, págs. 53 a 74, Madrid.

Lopez, J. M. 1985: Terra Sigillata Hispánica Tardia decorada. Acta Salmantiensis, 168. Salamanca.

Losada, H.; Donoso, R., 1965: Excavaciones en Segóbriga, Excavaciones Arqueológicas en España, 43, Madrid.

Luezas, R. A.; Saens, M. P., 1989: La cerámica romana de Varea, Gobierno de La Rioja, Instituto de Estudios Riojanos, Logroño.

MAOIOLI, M. G., 1983: La ceramica fine da mensa (Terra Sigillata), en Ravenna e il porto di Classe, Venti anni di ricerche archeologiche tra Ravennna in Classe Cord. por Vermond Montanari, Iovanna, University Press Bologna.

Martinez Rodriguez, F., 1989: Las cerámicas béticas de imitación tipo Peñaflor: bases para el estudio de un nuevo grupo cerámico de época altoimperial, Boletin de la asociación española de amigos de la arqueologia, 26, págs. 60-65, Madrid.

MAyet, F., 1975: La Ceramique a parois fines dans la Peninsule Iberique, Publications du Centre Pierre Paris, Paris.

Mayet, F., 1984: Les Céramiques Sigillées Hispaniques Publications du Centre Pierre Paris, Paris.

Mezquirız, M. A. 1961: Terra Sigillata Hispánica. Publicaciones de la Fundación Bryant, Valencia.

Mezquiriz, M. A. 1983: Tipología de la Terra Sigillata Hispánica, Boletín del Museo Arqueológico Nacional, Tomo I, núm. 2, págs. 123-131, Madrid.

Mezquirız, M. A. 1983: Cerámica Sigillata Hispánica. Historia y criterios tipológicos, Boletín del Museo Arqueológico Nacional, Tomo I, núm. 2, págs. 133-136, Madrid.

Mezquiriz, M. A. 1985: Terra Sigillata Ispánica, Atlante delle Forme Ceramiche, II Enciclopedia dell'Arte Antica, págs. $97-166$, Roma.

Molina FAJARDO, F., 1975: La sigillata paleocristiana autóctona y sus relaciones con la cerámica pintada, XIV Congreso Nacional de Arqueologia, págs. 999-1014, Zaragoza.

Molina, F., Huertas, C.; Ocaña, M. J., 1980: Cerro del Cortijo del Molino del Tercio, Moraleda de Zafayona (Granada), Noticiario Arqueológico Hispánico, 10, págs. 219-306, Madrid.

Nieto Gallo, GR.; Sánchez Meseguer, J.; Poyato Holgado, M. C. 1980: Oreto I, Excavaciones Arqueológicas en España, 114, Madrid.

Orfil.a, M., 1989: Cerámicas de la primera mitad del siglo v d. C., procedentes de la cisterna de Sa Mesquida (Santa Ponça, Mallorca), VI Convegno l'Africa Romana, págs.513-533, Sassari.

Orfila, M. (en prensa): ¿Producciones de cerámica sigillata no clásica en la Bética? Las llamadas sigillatas paleocristianas de Cástulo, IV Reunión de Arqueología Cristiana Hispánica, Lisboa, Sep. Oct. 1992.

Palol, P. DE; Cortes, J., 1974: La villa romana de la Olmeda, Pedrosa la Vega (Palencia). Acta Arqueológica Hispánica, 7. Madrid.

Paz Peralta, J. A., 1991: Cerámica de mesa romana de los siglos il al $v i d$. C. en la provincia de Zaragoza, Institución Fernando el Católico, Zaragoza.

Pérez Rodriguez. F.; Garcia Rozas, M. del R., 1989: Nuevos datos acerca de la producción de Terra Sigillata Tardía, Boletín del Seminario de Arte y Arqueología, LV, págs. 169-191, Valladolid.

Ramalı.o, S., 1984: Datos preliminares para el estudio de las cerámicas tardías de Begastri, Antigüedad y cristianismo, I, Begastri, págs. 71-84, Universidad de Murcia, Murcia. 
Roca Roumens, M., 1976: Sigillata hispánica producida en Andüjar (Jaén) Publicaciones del Instituto de Estudios Gienenses, Jaén.

Roca Roumens, M., 1981: Terra Sigillata Hispánica: una aproximación al estado de la cuestión, Cuadernos de Prehistoria, 6, págs. 385-411, Granada.

Rigiol, J., 1968: Les sigillées paleochrétiennes grises et orangées, Gallia, 26, págs. 177-244, Paris.

Ruiz, M.; MalPesa, M., 1982: Formas Hispánicas 52 y 55 procedentes de una Villa Romana de Úbeda (Jaén), Boletin del Instituto de Estudios Gienenses, 109, Jaén.

Sanchez-Lafuente Pérez, J., 1985: Comercio de cerámicas romanas en Valeria, Excma. Diputación Provincial de Cuenca, Cuenca.

Sanchez-Lafuente Pérez, J., 1990: Terra Sigillata de Segóbriga y ciudades del entorno: Valeria, Complutum y Ercavica, Ediciones de la Universidad Complutense de Madrid.

Serrano, E., 1979: Sigillata Hispánica en los hornos de Cartuja (Granada), en Studia Archaeologica. 57 , Valladolid.

Serrano, E., 1991: Terra Sigillata Hispánica de los alfares de Singilia Barba, Universidad de Málaga.

Serrano, E.; Atencia, R.; Rodriguez, P., 1984: Un nuevo taller de Sigillata en la Bética: Alameda (Málaga), Baetica, 7, págs. 171-184, Málaga.

Serrano, E.; De Luque, A., 1980: Memoria de la segunda y tercera campaña de excavaciones en la villa romana de Manguarra y San José. Cártama (Málaga), Noticiario Arqueológico Hispánica, 8 , págs. 253-396, Madrid.

Sotomayor, M., 1970: Siete hornos de cerámica romana en Granada con producción de sigillata, $X I$ Congreso Nacional de Arqueologia, págs. 713-728, Zaragoza.

Sotomayor, M., 1977: Marcas y estilos de la sigillata decorada de Andújar. Jaén.

Sotomayor, M., 1985: «La villa romana de Bruñel, en Quesada (Jaén)», Cuadernos de Prehistoria de la Universidad de Granada, núm. 10, págs. 335 a 366, Granada.

Sotomayor, M., Sola, A; Choclán, C., 1984: Los más antiguos vestigios de la Granada Ibero-romana y Arabe, Granada

TED'A (Taller Escola D'Arqueologia), 1989: Un abocador del segle v d. C. en el Fòrum Provincial de Tàrraco, en Memories d'excavació, 2. Tarragona.

Tuset, F., 1991: La Terra Sigillata de Clúnia. Una propuesta metodológica para el estudio de las producciones altoimperiales. Tesis inédita dactolografiada. Barcelona.

Valiente Canovas, S., 1981: Pico de La Muela (Valera de Abajo, Cuenca), Noticiario Arqueológico Hispánico, 12 , págs. 85 a 134 , Madrid.

VernhET, A., 1977: Les dernières productions de la Graufesenque et la question des sigillées claires B, Figlina, 2, págs. 33 a 49 , Lyon.

Whitehause, D.; Barker, G.; Reece, R.; Reese, D. 1982: The Schola Praeconum I: The coins, pottery, lamps and fauna, en Papers of the British School at Rome, Vol. L, págs.53-101, Londres.

Whitehause, D.; Constantino, L.; Ghuidobaldi, F.; Passi, S.; Pensabene, P. ; Pratt, S.; Reece, R.; Reese, D. 1985: The Schola Praeconum II, en Papers of the British School at Rome, Vol. LIII, págs. 163-210, London. 